\title{
Comparison of the emission factors measured in real world driving with those of COPERT 4
}

\author{
J. M. López ${ }^{1}$, N. Flores ${ }^{1}$, J. Lumbreras ${ }^{2} \&$ R. Villimar ${ }^{2}$ \\ ${ }^{1}$ University Institute for Automobile Research (INSIA), UPM, Spain \\ ${ }^{2}$ Department of Chemical \& Environmental Engineering, UPM, Spain
}

\begin{abstract}
The aim of the paper is to compare $\mathrm{CO}, \mathrm{HC}, \mathrm{NOx}, \mathrm{PM}$ and greenhouse gas emissions for different urban buses regarding the Euro standard. Three buses were tested, two of them covering the range from Euro III to Euro IV emissions standards, and another one meeting the EEV standard. On-board emission measurements in urban buses were conducted in real world driving routes, operated by the Madrid Municipal Transport Company (EMT), in the city of Madrid. Therefore, the paper examines the real-world efficiency of the emission control technologies conducting tests under real-world driving cycles. It also shows a comparison in emissions and fuel consumption regarding the type of fuel used. The fuels analyzed are diesel and Compressed Natural Gas (CNG). Finally, the test results obtained directly from the on-board measurements were compared with those results obtained from the application of the COPERT model and another model developed by INSIA to estimate the fuel consumption and pollutant emissions generated by the urban bus fleet of Madrid.

Keywords: on road measurements, emission factors, urban buses.
\end{abstract}

\section{Introduction}

On road emissions from urban traffic are one of the major environmental problems in large European capitals. In the city of Madrid, and according to the inventories published by the City Council (MCC [1]), road transport is responsible for over $50 \%$ of $\mathrm{CO}_{2}$ emissions, $75 \%$ of NOx emissions, $90 \%$ of $\mathrm{CO}$ emissions, and 30\% of the emissions from Volatile Organic Compounds (VOC).

Emissions standards for vehicles have included significant emission reduction for many pollutants. Engines from Heavy Duty vehicles are also subject to strict 
controls. Global emission limits for mobile heavy-duty diesel engines are becoming increasingly stringent. Due to growing concerns about NOx and particulate matter (PM) emissions from diesel engines, stricter regulations are being implemented which require advanced emission control technologies. In response to this trend, diesel vehicle manufacturers have been testing and applying various emission control technologies to mobile applications.

Currently, with regard to the fuel used, the only viable solution for diesel substitution is the Fatty Acid Methyl Esters (FAME), commonly known as biodiesel. Compared to fossil diesel, it is biodegradable and its combustion reduces the most harmful exhaust emissions, including carbon monoxide, unburned hydrocarbon, and particulate matter. However, several approaches showed that the use of biodiesel does not reduce nitrogen oxides emissions (Lopez et al. [2], Canakci et al. [3], Tzirakis et al. [4]).

\section{Methodology}

Although chassis dynamometer drive cycles exist for heavy duty vehicles (Nylund et al. [5]), on-road tests are being used to evaluate the development of exhaust after-treatment system under real-world operating conditions in the vehicle (Pelkmans and Debal [6], Frey et al. [7]). In this paper, two driving cycles were conducted to evaluate emissions and fuel consumption over conventional urban buses with on-board measurement equipments.

Five tests were run for each vehicle. The five sets of readings were statistically analyzed to assess the validity of the results. Emission data usually vary from test to test, due to the variation in driver performance, external conditions, and engine and after-treatment temperatures.

Test results were compared with the results obtained by applying two different emission models. The first one is the COPERT model (Gkatzoflias et al. [8]), the reference model used in Europe (EEA [9]). It was applied for the different Euro buses with a similar driving cycle to the real world conditions regarding speed and distance travelled.

The second model was developed by INSIA (Lopez et al. [10]) and allows the estimation of fuel consumption and emissions generated by the urban bus fleet of Madrid. It has been calibrated with on-board emission measurements conducted in real-world driving routes operated by the Madrid Municipal Transport Company (EMT). This model requires a given distance-speed profile. To obtain this input, on-board experimental tests were realized in 8 buses, covering the range from Euro II to Euro IV and EEV (2 buses of each Euro standard). Their behaviour was evaluated taking into account the load, fuel, slope and speed in real operating conditions. Driving cycles were 3 specific driving routes in the city of Madrid, selected in accordance with the EMT in terms of representation and variability (figure 1). 

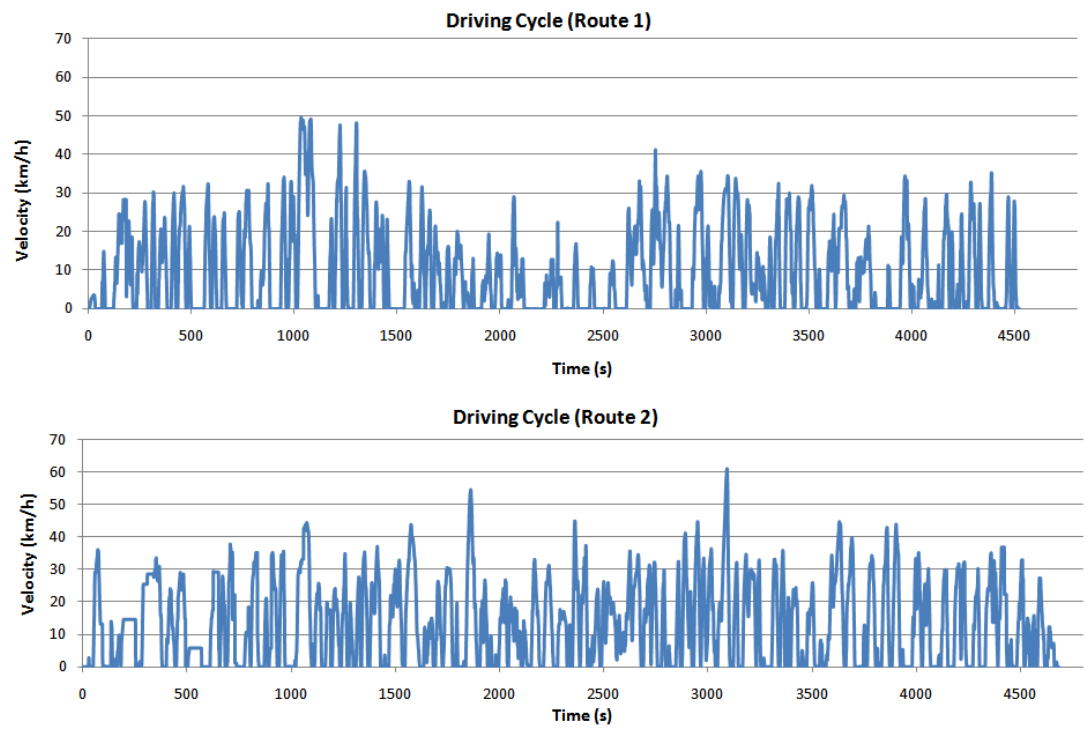

Figure 1: Driving cycles.

\subsection{Experimental setup}

Three urban buses were employed in this study. They were classified in the following groups according to similar behaviour depending on its treatment system (Euro emissions standard) and fuel used:

- Buses with Euro III standard and diesel.

- Buses Euro IV standar and diesel.

- Buses EEV standard and natural gas.

Since there were buses from different manufacturers the most representative were selected. Table 1 shows the technical specifications of the tested vehicles.

Table 1: $\quad$ Technical specifications for test vehicles.

\begin{tabular}{|c|c|c|c|}
\cline { 2 - 4 } \multicolumn{1}{c|}{} & Vehicle 2 & Vehicle 3 & Vehicle 4 \\
\hline Euro standard & Euro III & Euro IV & EEV \\
\hline Come into service & 2002 & 2008 & 2008 \\
\hline Power (kW) & 213 & 199 & 228 \\
\hline Cylinders / Displacement & $6 / 7,790$ & $6 / 10,518$ & $6 / 11,967$ \\
\hline Weight (kg) & 12,300 & 12,180 & 19,000 \\
\hline Weight / Power & 57.75 & 61.21 & 83.33 \\
\hline Representativeness (\%2009 urban fleet) & $42.7 \%$ & $25.0 \%$ & $13.8 \%$ \\
\hline Representativeness (\%2008 urban fleet) & $43.7 \%$ & $24.5 \%$ & $16.3 \%$ \\
\hline
\end{tabular}


The experimental tests were conducted along two urban driving routes operated by the Municipal Transport Company (EMT). In both cases, the test procedure consisted of following another EMT bus during working hours and making each bus trip several times a day, on different days at the same hour and with the same driver. The main features of the two driving cycles are described in Table 2.

Table 2: $\quad$ Features of the driving cycles routes.

\begin{tabular}{|l|c|c|c|}
\hline & Distance $(\mathrm{km})$ & Average Speed & $\mathrm{N}^{\mathrm{o}}$ bus stops \\
\hline Route 1 & 11.9 & 10.2 & 38 \\
\hline Route 2 & 17.3 & 13.3 & 64 \\
\hline
\end{tabular}

\subsection{Measurement equipments}

Exhaust emissions have been measured using the Horiba OBS 2200 on board emission measurement system. It measure instantaneous emissions under real driving conditions for $\mathrm{CO}, \mathrm{CO}_{2}, \mathrm{THC}$ and $\mathrm{NOx}$, fuel consumption and speed. It provides real mass emission results $(\mathrm{g} / \mathrm{s})$ and instantaneous emissions (expressed as a $\%$ or rpm, depending on the gas involved). The analyzers are:

- Multiple $\mathrm{CO}, \mathrm{CO}_{2}$ and $\mathrm{H}_{2} \mathrm{O}$ analyzer based on the Heated Non-Dispersive Infra-Red method (HNDIR).

- $\quad$ THC analyzer based on the Heated Flame Ionization Detection method (HFID).

- $\quad$ NOx analyzer based on the Heated Chemiluminescent Detection method (HCLD).

The equipment also incorporates an exhaust gas flow meter that includes a calibrated pipe with its Pitot tubes, the sample gas outlet and the temperature sensor, as can be seen in figure 2 .
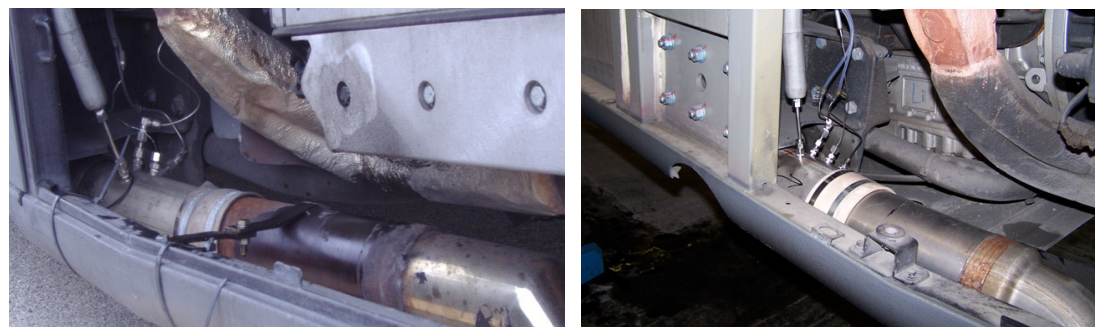

Figure 2: $\quad$ Exhaust gas flow meter with its Pitot tubes.

By using the carbon balance method, fuel consumption can be very accurately determined from mass emissions of $\mathrm{CO}, \mathrm{CO}_{2}$ and THC.

The equipment also includes sensors to measure humidity and ambient temperature and a GPS system for measuring speed and position. This speed 
measurement has been verified using a Correvit L-CE-non-contact speed sensor finding a deviation lower than $1 \mathrm{~km} / \mathrm{h}$.

An EIU (External Input Unit) is also integrated with free analog sports to connect other equipments that allow the connection of a particle measurement device. This device is the MAHA DPMS-04, and provides particle concentration in $\mathrm{mg} / \mathrm{m}^{3}$ by laser technology, that can be expressed in $\mathrm{g} / \mathrm{s}$. Figure 3 shows an example of the installation of the measurement equipments inside a bus.
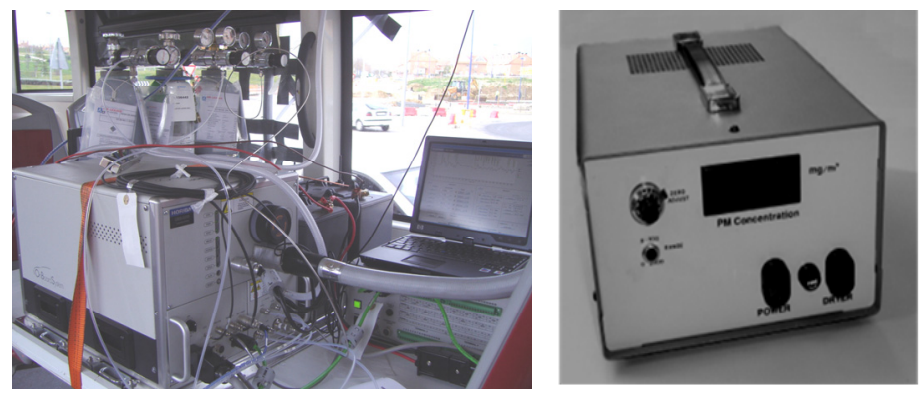

Figure 3: Installation of the measurement equipments: HORIBA OBS 2200 (left) and MAHA DPMS 04 (right).

\section{Results}

Results for $\mathrm{CO}, \mathrm{HC}, \mathrm{NOx}, \mathrm{PM}$ and $\mathrm{CO}_{2}$ emissions and fuel consumption for each driving cycle were obtained from three types of engine with two different fuels (diesel and GNC). PM emissions from natural gas vehicles have not been measured because MAHA devices are only applicable to diesel vehicles.

Route 1 (Test results)

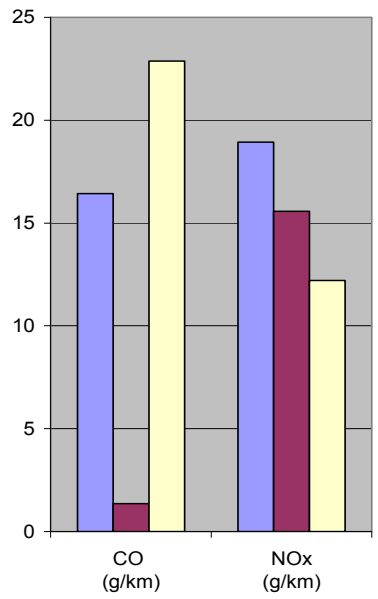

$\square$ Test Euro III $\square$ Test Euro IV $\square$ Test GNC

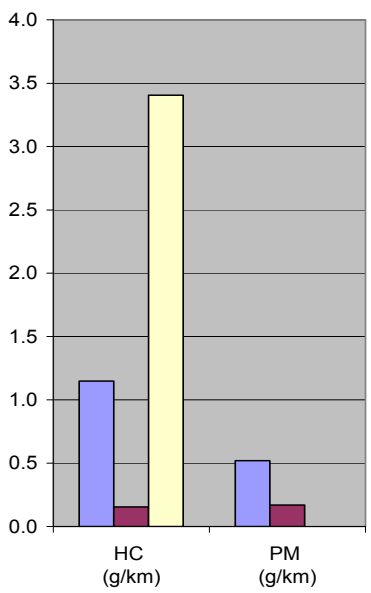

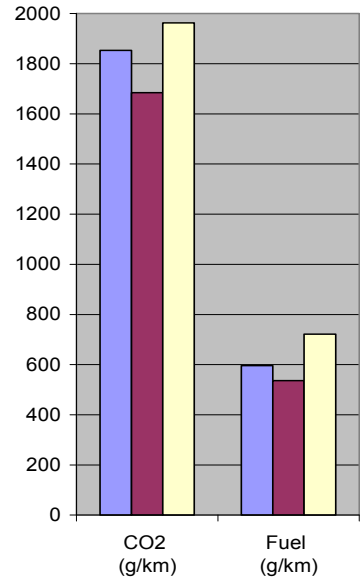

Figure 4: Results of on-board measurement tests (route 1). 
Figures 4 to 7 show the comparative results obtained for route 1, and figures 8 to 11 show those obtained for route 2 . In both cases, the average results from onboard measurements were compared with corresponding emission factors derived from COPERT 4 calculations for urban, hot stabilized conditions and average speed of $10.2 \mathrm{~km} / \mathrm{h}$ (route 1 ) and $13.3 \mathrm{~km} / \mathrm{h}$ (route 2 ). It can be shown that results estimated by the model developed by INSIA are consistent with the results obtained from the measurements tests.
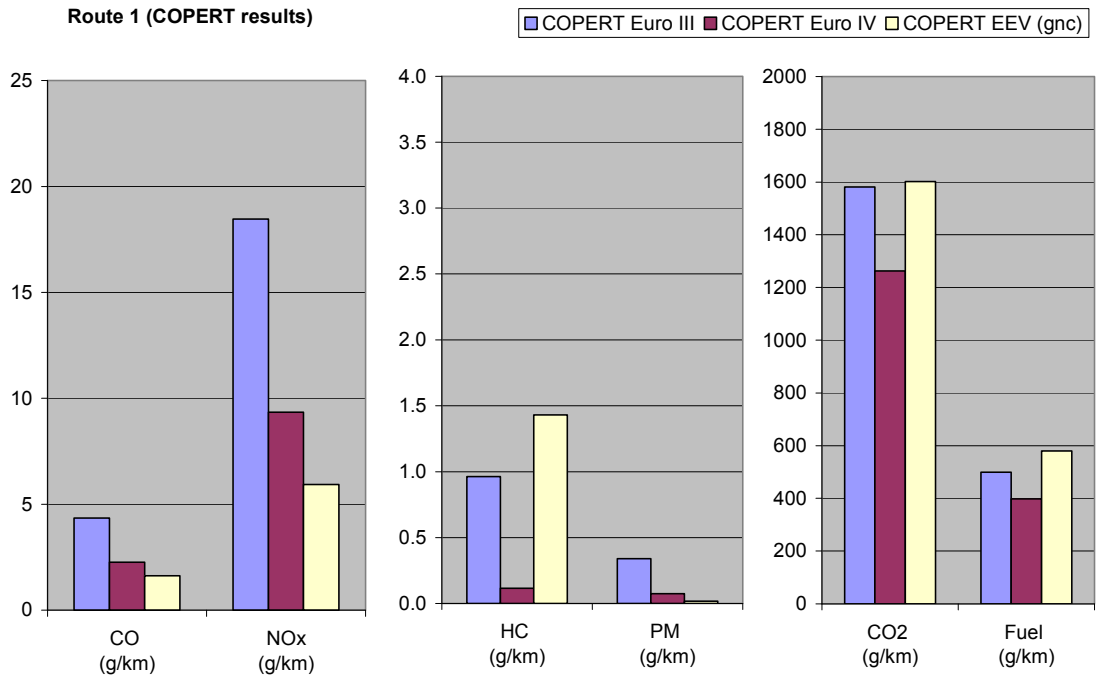

Figure 5: $\quad$ Results by applying the COPERT model (route 1).
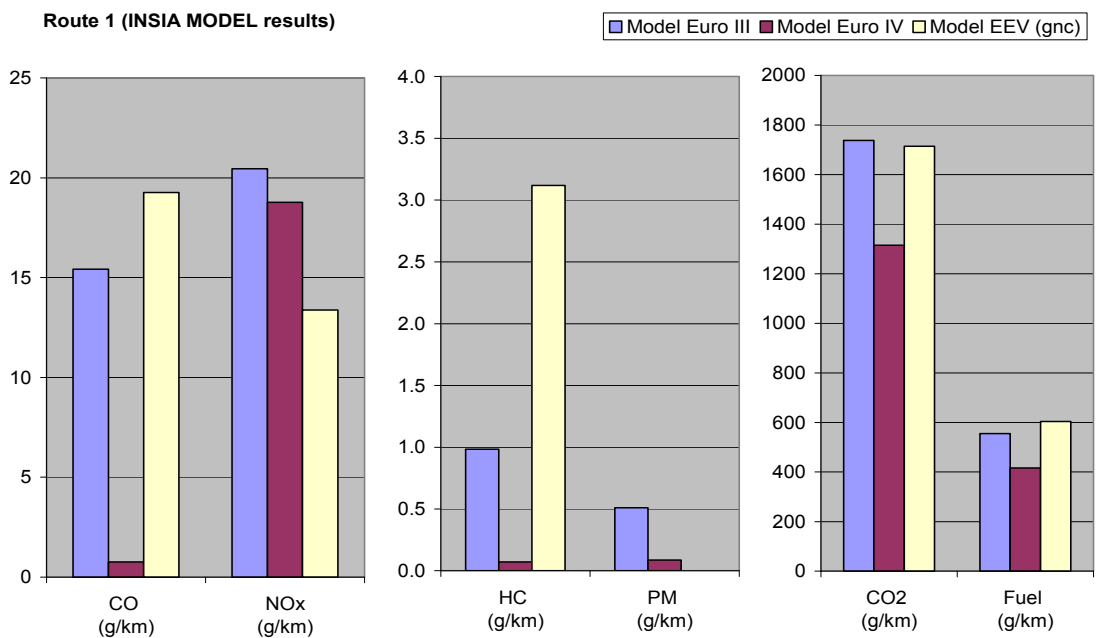

Figure 6: Results by applying the model developed by INSIA (route 1). 
Carbon monoxide (CO): $\mathrm{CO}$ emissions are reduced from Euro III to Euro IV standard vehicle. This reduction is directly related to the introduction of exhaust after-treatment systems. For natural gas vehicles, results are higher mainly due to the work of the spark ignition engine with stoichiometric mixture and in transient conditions most of the driving cycle.

Nitrogen oxides (NOx): NOx emissions are also reduced from Euro III to Euro IV standard vehicle, which is related to the exhaust after-treatment systems. Values with natural gas engines have a lower value.

Unburned Hydrocarbons (HC): $\mathrm{HC}$ emissions are also reduced due to the introduction of exhaust after-treatment systems. For natural gas vehicles, the values of $\mathrm{HC}$ emission are higher for being a spark ignition engine with stoichiometric mixture. These emissions are primarily methane.

Particulate Matter (PM): PM emissions have the same trend. The reduction is also directly related to the improvements in exhaust after-treatment systems. For natural gas values are not shown because the measurement device cannot be applied to this kind of engines. However, PM concentrations are much lower and caused by the combustion of oil dilution.

Fuel consumption and $\mathrm{CO}_{2}$ : It is observed a reduction of fuel consumption and $\mathrm{CO}_{2}$ emissions in Euro IV standard vehicles respect to Euro III standard vehicles, despite the increase of exhaust back pressure as a result of aftertreatment systems installed in the exhaust pipe. Natural gas vehicles gave higher fuel consumption due to its lower volumetric efficiency, quantitative load regulation, very unfavorable in urban traffic, and stoichiometric mixture.
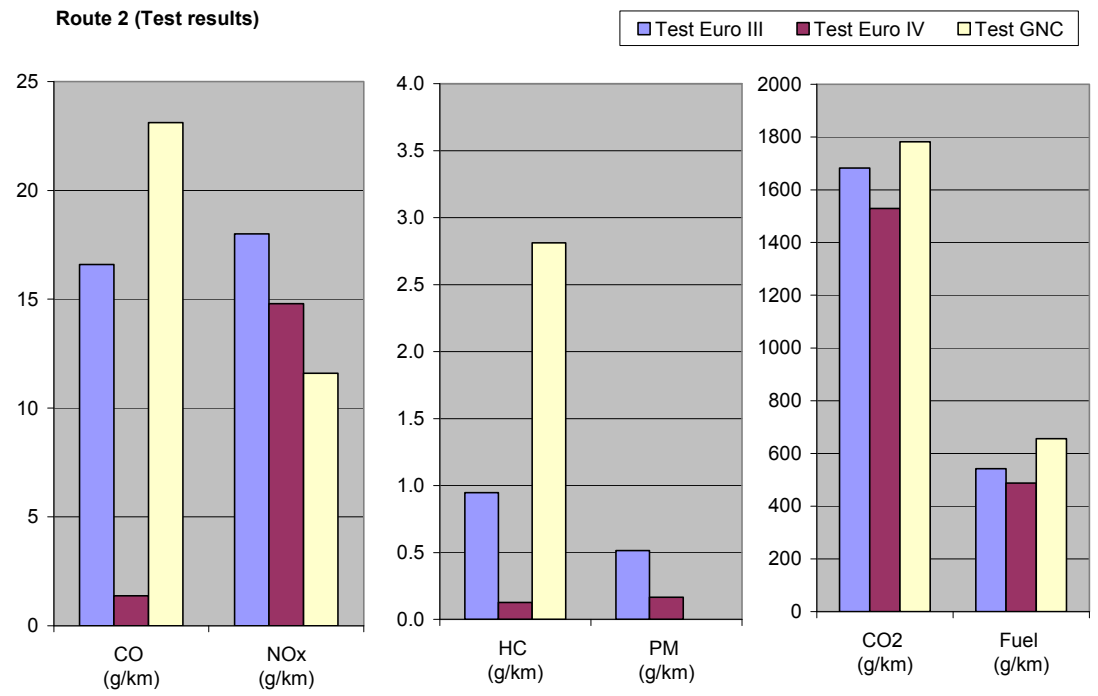

Figure 7: Results of on-board measurement tests (route 2). 
Route 2 (COPERT results)

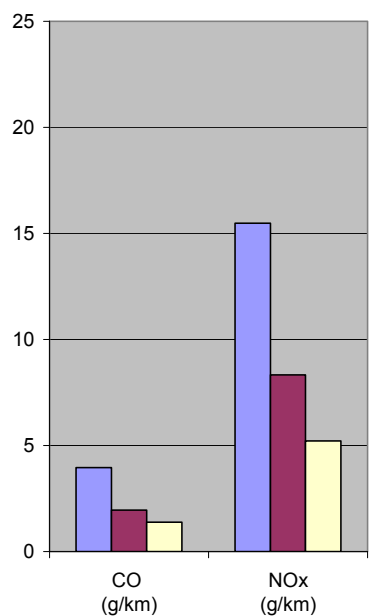

$\square$ COPERT Euro III $\square$ COPERT Euro IV $\square$ COPERT EEV (gnc)
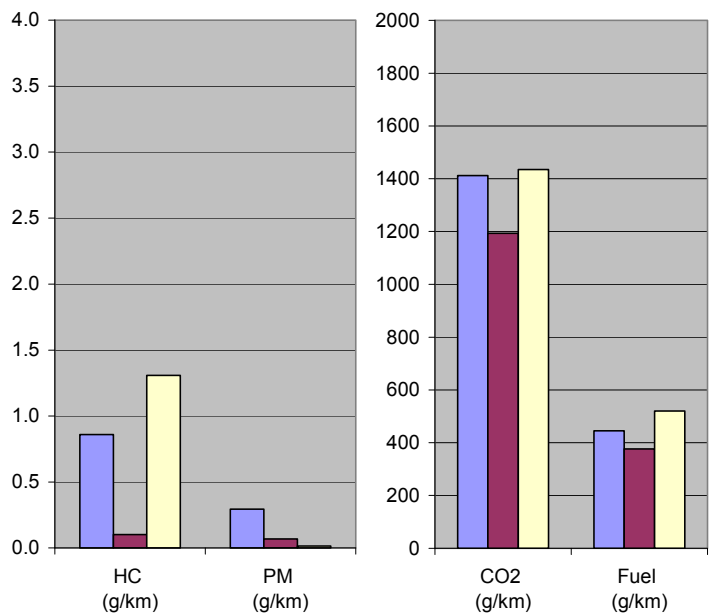

Figure 8: $\quad$ Results by applying the COPERT model (route 2).

Route 2 (INSIA MODEL results)

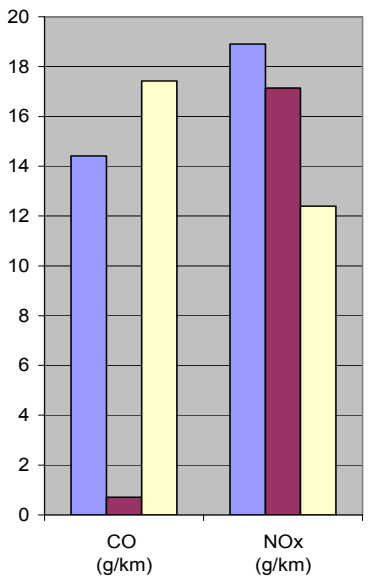

$\square$ Model Euro III $\square$ Model Euro IV $\square$ Model EEV (gnc)

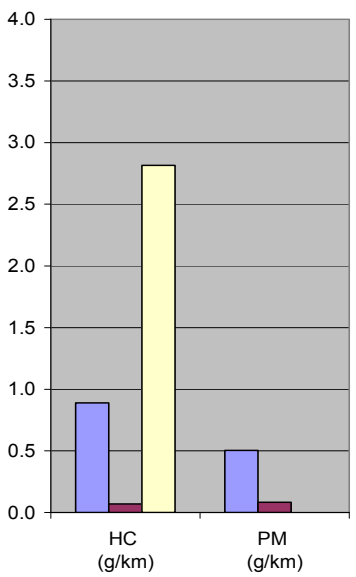

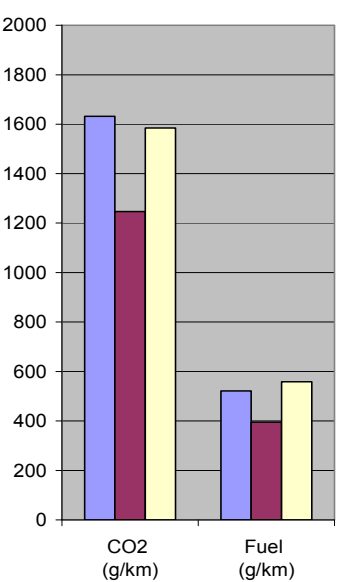

Figure 9: $\quad$ Results by applying the model developed by INSIA (route 2).

Table 3 shows the comparison between results obtained from the experimental test, COPERT model and the model developed by INSIA.

\section{Conclusions}

The aim of the paper is to compare $\mathrm{CO}, \mathrm{HC}, \mathrm{NOx}, \mathrm{PM}$ and greenhouse gas emissions for different urban buses regarding the Euro standard. Three buses 
Table 3: $\quad$ Emission and fuel consumption results in $\mathrm{g} / \mathrm{km}$.

\begin{tabular}{|c|c|c|c|c|c|c|}
\hline & $\begin{array}{c}\mathrm{CO}_{2} \\
(\mathrm{~g} / \mathrm{km})\end{array}$ & $\begin{array}{c}\mathrm{CO} \\
(\mathrm{g} / \mathrm{km})\end{array}$ & $\begin{array}{c}\mathrm{HC} \\
(\mathrm{g} / \mathrm{km})\end{array}$ & $\begin{array}{c}\text { NOx } \\
(\mathrm{g} / \mathbf{k m})\end{array}$ & $\begin{array}{c}\text { PM } \\
(\mathrm{g} / \mathrm{km})\end{array}$ & $\begin{array}{c}\text { Fuel } \\
(\mathrm{g} / \mathrm{km})\end{array}$ \\
\hline \multicolumn{7}{|c|}{ TEST RESULTS } \\
\hline \multicolumn{7}{|c|}{ Route 1} \\
\hline Euro II & 1695.13 & 23.71 & 0.61 & 16.10 & 0.32 & 548.94 \\
\hline Euro III & 1852.76 & 16.43 & 1.15 & 18.93 & 0.52 & 596.22 \\
\hline Euro IV & 1683.77 & 1.36 & 0.15 & 15.56 & 0.17 & 536.34 \\
\hline GNC & 1962.11 & 22.87 & 3.41 & 12.20 & - & 721.30 \\
\hline \multicolumn{7}{|c|}{ Route 2} \\
\hline Euro II & 1539.43 & 23.96 & 0.50 & 15.31 & 0.31 & 499.30 \\
\hline Euro III & 1682.58 & 16.60 & 0.95 & 18.00 & 0.51 & 542.30 \\
\hline Euro IV & 1529.12 & 1.37 & 0.13 & 14.80 & 0.17 & 487.84 \\
\hline GNC & 1781.89 & 23.11 & 2.81 & 11.60 & 0.00 & 656.08 \\
\hline \multicolumn{7}{|c|}{ COPERT 4 RESULTS } \\
\hline \multicolumn{7}{|c|}{ Route 1} \\
\hline Euro II & 1497.98 & 4.22 & 1.12 & 17.49 & 0.31 & 472.63 \\
\hline Euro III & 1580.62 & 4.35 & 0.96 & 18.46 & 0.34 & 498.70 \\
\hline Euro IV & 1262.29 & 2.26 & 0.11 & 9.34 & 0.07 & 398.26 \\
\hline $\mathrm{GNC}$ & 1602.15 & 1.62 & 1.43 & 5.93 & 0.02 & 580.35 \\
\hline \multicolumn{7}{|c|}{ Route 2} \\
\hline Euro II & 1340.02 & 3.72 & 0.98 & 15.51 & 0.27 & 422.79 \\
\hline Euro III & 1412.63 & 3.97 & 0.86 & 15.48 & 0.29 & 445.70 \\
\hline Euro IV & 1193.33 & 1.96 & 0.10 & 8.33 & 0.07 & 376.51 \\
\hline GNC & 1435.16 & 1.39 & 1.31 & 5.22 & 0.01 & 519.86 \\
\hline \multicolumn{7}{|c|}{ MODEL RESULTS developed by INSIA } \\
\hline \multicolumn{7}{|c|}{$\begin{array}{c}\text { Route } 1 \\
\end{array}$} \\
\hline Euro II & 1405.14 & 15.41 & 0.38 & 15.65 & 0.16 & 454.42 \\
\hline Euro III & 1737.60 & 15.42 & 0.99 & 20.45 & 0.51 & 555.49 \\
\hline Euro IV & 1314.81 & 0.76 & 0.07 & 18.77 & 0.09 & 416.46 \\
\hline GNC & 1713.99 & 19.26 & 3.12 & 13.38 & 0.00 & 604.21 \\
\hline \multicolumn{7}{|c|}{ Route 2} \\
\hline Euro II & 1318.94 & 14.68 & 0.34 & 14.54 & 0.15 & 426.41 \\
\hline Euro III & 1631.55 & 14.41 & 0.89 & 18.90 & 0.50 & 521.52 \\
\hline Euro IV & 1246.53 & 0.71 & 0.07 & 17.14 & 0.08 & 394.83 \\
\hline GNC & 1584.24 & 17.42 & 2.82 & 12.40 & - & 558.04 \\
\hline
\end{tabular}

were tested, two of them covering the range from Euro III to Euro IV emissions standards, and another one meeting the EEV standard.

Test results show a similar trend for $\mathrm{HC}, \mathrm{NOx}, \mathrm{PM}, \mathrm{CO}_{2}$ and fuel consumption for the technology classes (from Euro III to Euro IV, and EEV). In this respect, there was a good agreement between the two methods, although values given by COPERT were systematically lower than those from 
experimental tests (as in Ekström et al. [11]). Despite this good agreement, the largest discrepancies were found in natural gas vehicles, especially in $\mathrm{CO}$ and $\mathrm{HC}$ emissions, but also in NOx emissions.

As for $\mathrm{CO}$ emissions, the agreement was less favorable, being overestimated by experimental tests. This trend was found in all technologies classes except in Euro 4 standard bus. This difference may be due to the dispersion of this pollutant in these engines. Therefore, it is necessary to analyze the methodology used in the INSIA model for estimating $\mathrm{CO}$ emissions in order to study in greater depth the spread and variability of this component in test measurements.

\section{References}

[1] MCC (Madrid City Council). Emission inventory for Madrid. 2010.

[2] López, J.M., Aparicio, F., Flores, N., Jiménez, F., Análisis comparativo de las emisiones contaminantes de diferentes tipos de autobuses según su norma anticontaminante en ciclo de conducción real. Presentation to 9th Congreso Iberoamericano de Ingeniería Mecánica (CIBIM), November 17th, 2009.

[3] Canakci, M., Erdil, A., Arcaklioghu, E., Performance and exhaust emissions of a biodiesel engine. Applied Energy 83, pp. 594-605, 2006.

[4] Tzirakis, E., Karavulakis, G., Zannikos, F., and Stournas, S., Impact of diesel/biodiesel blends on emission from a diesel vehicle-operated in real driving conditions. SAE Paper $\mathrm{N}^{\circ}$. 2007-01-0076, 2007.

[5] Nylund, N., Erkkilä, K., Lappi, M., and Ikonen, M., Transit bus emission study: comparison of emissions from diesel and natural gas buses. Research report VTT, 2004.

[6] Pelkmans, L., Debal, P., Comparison of on-road emission with emissions measured on chassis dynamometer test cycles. Transportation Research Part D 11, pp. 233-241, 2006.

[7] Frey, H., Rouphail, N., Zhai, H., Farias, T., and Gonçalves, G., Comparing real-world fuel consumption for diesel-and hydrogen-fueled transit buses and implication for emissions. Transportation Research Part D 12, pp. 281291, 2007.

[8] Gkatzoflias, D., Kouridis, C., Ntziachristos, L., Samaras, Z., COPERT 4, Computer Programme to Calculate Emissions from Road Transport. Aristotle University Thessaloniki/European Environment Agency, 2007.

[9] EEA (European Environment Agency), EMEP/EEA Air pollution emission inventory guidebook - 2009. Technical report $N^{\circ}$ 9, 2009.

[10] López, J.M., Jiménez, F., Aparicio, F., Flores, N., Paez, J. Tapia, S., Quantification of the environmental impact in the city of Madrid depending on technical measures applied to bus fleet. FISITA, WAC, May $30^{\text {th }}, 2010$.

[11] Ekström, M., Sjödin, A., and Andreasson, K., Evaluation of the COPERT III emission model with on-road optical remote sensing measurements. IVL Swedish Environmental Research Institute Ltd., Atmospheric Environment 38, pp. 6631-6641, 2004. 